\title{
BMJ Open Deaths and major biographical events: a study of all cancer deaths in Germany from 1995 to 2009
}

\author{
Daniel Medenwald, ${ }^{1}$ Oliver Kuss ${ }^{2,3}$
}

To cite: Medenwald D, Kuss 0. Deaths and major biographical events: a study of all cancer deaths in Germany from 1995 to 2009. BMJ Open 2014;4:e004423. doi:10.1136/bmjopen-2013004423

- Prepublication history and additional material is available. To view please visit the journal (http://dx.doi.org/ 10.1136/bmjopen-2013004423).

Received 7 November 2013 Revised 24 February 2014 Accepted 27 February 2014

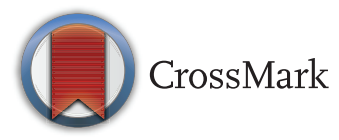

${ }^{1}$ Institute of Medical Epidemiology, Biostatistics and Informatics, University of Halle-Wittenberg, Halle (Saale), Germany ${ }^{2}$ Institute for Biometrics and Epidemiology, German Diabetes Center, Leibniz Institute for Diabetes Research at Heinrich Heine University, Düsseldorf, Germany

${ }^{3}$ Faculty of Medicine, Centre for Health and Society, Heinrich Heine University, Düsseldorf, Germany

Correspondence to Daniel Medenwald; daniel. medenwald@uk-halle.de

\section{ABSTRACT \\ Objective: To determine if people dying from cancer are able to prolong their own life in order to experience a certain biographical event, or whether the appearance of such an occasion leads to increased deaths before the event.}

Methods: We compared numbers of cancer deaths during a period of 1 week before and after biographically important occasions, which were birthday, Christmas and Easter. As a psychogenic postponement or hastening of death is most likely in chronic diseases (as opposed to accidents or cardiovascular events), we included cancer deaths only. We estimated relative risks (RRs) with their corresponding Bonferroni corrected Cls to assess effects of biographical events. All registered cancer deaths in Germany from 1995 to 2009 were included (3 257520 individual deaths). Numbers of deaths were corrected for seasonality. Results: Considering all cases, there were noticeably more deaths than expected in the week preceding Christmas, leading to an RR of dying after the event of 0.987 ( $\mathrm{Cl} 0.978$ to 0.997). Estimates indicating a hastening of death were consistent over several subgroups. Other occasions showed inconsistent results, especially there was no convincing postponement effect in our data.

Conclusions: While there is no evidence of different death numbers before and after Easter and birthdays, the appearance of Christmas seems to increase deaths.

\section{INTRODUCTION}

Feasts, holidays and meaningful events play an important role in people's lives. It is an obvious question whether this importance is maintained until the last moments of life, leading to a change of mortality pattern around the event.

During the last moments of their life patients are often under high psychological pressure. Previous studies found an escalation of distress and depressive symptoms before death in patients with cancer. ${ }^{12}$ A study by Allen-Mersh et $a l^{\beta}$ gives evidence of an impaired survival in patients showing depressive symptoms. The authors discussed an interaction of psychological mood and immune function. ${ }^{4}$ Male and female patients with cancer perceive disease-related distress differently. ${ }^{5}{ }^{6}$ An

\section{Strengths and limitations of this study}

- Large number of included deaths encompassing an entire country leading to a sufficient statistical power.

- Seasonality and further biasing effects were taken into account.

- Examination of several events and subgroups.

- Retrospective character of the study merely using register data.

increased distress-induced activity of the hypothalamic-pituitary axis (HPA) leads to a reduced natural killer cell activity and thus tumour control. ${ }^{2} 7$ In head and neck cancer poorer psychosocial functioning (including depressive symptoms, perceived stress, anxiety and social support) was associated with a greater expression of vascular endothelial growth factor (VEGF), which itself triggers tumour growth by inducing angiogenesis. ${ }^{8}$ However, demographic parameters such as marital status, age and sex were not associated with VEGF expression.

Positive expectations towards approaching holidays/biographically important events might be associated with a relief from the chronic distress in patients with cancer leading to a reduction in HPA activity. As chronic maladies are more easily affected by social and psychological factors than acute diseases, cancer-related deaths have the potential to draw reliable conclusions of possible postponement effects. Assuming that patients with cancer are under continuous (dis)stress two mechanisms, acting in opposite directions, might be working:

1. A reduction of distress prior to an event leading to more deaths after the event.

2. An increase of distress before an event reflected by more deaths before the event.

More generally, social support was related to tumour survival; the lack of a partner was associated with a reduced quality of life ${ }^{9}$ and worse prognosis. ${ }^{10}$ However, in patients with breast cancer Kornblith et $a l^{11}$ revealed that 
social support has to be very high to cause an improvement of distress.

Concerning cancer treatment, patients with helpless attitudes might receive less healthcare than they require to experience maximum survival and this aspect might be influenced by major holidays due to, for example, staff shortage. ${ }^{12}$ As shown recently, married people receive better treatment than their unmarried counterparts and thus have a better prognosis. ${ }^{13}$

Despite these social and psychological aspects, there is also a behavioural component when explaining possible postponement effects: ${ }^{14}$ reduced physical activity and inadequate food intake (probably most prevalent on and around major holidays) might have serious consequences on patients with cancer. ${ }^{15-18}$

Also malignancy is a relevant point in patients with cancer, as a very malignant neoplasm might be less 'controllable' by patients with cancer and thus we would observe smaller effects in this subgroup as compared with the subgroup of decedents with less malignant tumours.

The holidays discussed here are Christmas and Easter, which have a strong religious aspect and birthdays, which are mainly a secular event. In Germany, Christmas and Easter are of high importance and serve as opportunities when families come together and people experience solidarity. Even more, these events are legal holidays where people have several days off.

In recent decades several studies have tried to address these issues: a few of them are reviewed in the following paragraphs.

\section{Birthdays}

Recently, Shimizu and Pelham ${ }^{14}$ investigated more than 30000000 decedents from the USA. This study revealed a decline in mortality in the month preceding the birthday and an increase in the month of birth. Unfortunately, the authors did not review this more closely by, for example, performing stratified analyses for age or sex. Nevertheless, they compared adults and children and found a weaker drop-peak pattern in the former. By examining a relatively large sample of 1435815 individuals, Phillips $e t a l^{16}$ demonstrated a rise in mortality for women after their birthday. In contrast, men died more frequently before their birthday. Byers et $a l^{19}$ found a pattern of increased deaths after the birthday, which was significant in individuals who had never been married.

Because of the possible distractions due to cardiovascular diseases, the following studies concentrated on patients with cancer. Brown and Knapp ${ }^{20}$ analysed sex, cancer diagnosis and month of death in a collective from the states of New York and Ohio in the USA. Though they found that more deaths occurred after the birthday in several instances (eg, a preproportion/postproportion of $37.3 \% / 62.7 \%$ in April 1989 in Ohio), their results were inconsistent and were not corrected for multiple testing. Out of 190 separately conducted statistical tests, only 10 were statistically significant, closely corresponding to the expected $5 \%$ level of significance if the null hypothesis of no birthday effect is assumed to be true. Young and Hade ${ }^{21}$ examined a large sample in terms of the mortality affiliated to Christmas, birthdays and Thanksgiving. Despite the inclusion of 309221 cases, only in two subgroups was a postponement statistically significant. The estimated effects were very small as the deviation from a homogeneous preproportion/postproportion was below $2 \%$ for almost all of the 21 features tested. Again, the findings were not adapted for multiple testing, which would explain the significance.

One further aspect is worth mentioning here: referring to a study by Alderson, ${ }^{22}$ Roger $^{23}$ gave a feasible explanation for an apparent postponement around their birthday in elderly people. Because daily mortality decreases successively from an age of about 75 years, the highest death rates occur immediately after crossing the lower limit of an age group. As the considered event and the group threshold are identical in the analyses of birthday and age, it seems natural that there are more deaths in the period directly following the birthday.

\section{Christmas and Easter}

An augmentation of deaths at Christmas, especially due to reasons related to cardiac conditions, was found in several studies. ${ }^{24-26}$ Phillips $e t a l^{4}$ observed 1023 more deaths from diseases of the circulatory system at Christmas, while cancer deaths declined slightly by $0.8 \%$, when all settings were considered. There was almost no deviation from the expected number of cancer deaths at New Year. The authors discussed several explanations, such as increased respiratory diseases, emotional stress and staff shortages. ${ }^{24-26}$ A similar peak at Christmas was not found in the data analysed by Milne, ${ }^{27}$ but rather on New Year's Day. Shimizu and Pelham ${ }^{14}$ observed a decrease and postponement of deaths at Christmas in adults living in the USA. The number exceeding the expected level in the 2 days following Christmas was approximately $3 \%$, and the effects were stronger in children. Considering only cancer deaths, Young and $\mathrm{Hade}^{21}$ were not able to identify a convincing deferral or hastening of death.

Only some studies have been conducted to analyse mortality on and around Easter. One of the few studies undertaken could not find any augmentation of deaths at Easter. ${ }^{27}$ The mortality of 1038 Roman Catholic priests at Easter and Christmas was the subject of another study, which however failed to find any 'meaningful pattern of death'. ${ }^{28}$

\section{Limitations of previous studies}

Judging from previously conducted studies, it is essential to consider the following points:

1. It is crucial to achieve a sufficient statistical power. The power of previous studies ${ }^{20}{ }^{21}$ does not seem to 
have been large enough to detect small deviations below $1 \%$ from an equal predeviation/postdeviation.

2. Samples that do not exclude acute diseases should be treated with caution. Otherwise, short-term physiological distractions are unavoidable and possible deferrals cannot be fully attributed to an actual will to live. A feasible solution is to include only deaths from cancer. ${ }^{20} 21$

3. Consideration of seasonal trends of death numbers is important. For example, Young and Hade ${ }^{21}$ checked for possible trend effects in the data. They found a U-shaped trend for overall deaths, but not for deaths caused by cancer. Thus, they did not correct for seasonal trends in their analysis. However, the necessity to control for trend effects is generally implied by higher winter mortality. ${ }^{29}$

4. Preferably, the data should encompass a whole country, as many previous studies often used only local data. ${ }^{19-21}$

5. When age groups are built it is essential to exclude the dividing biographical date from the analysed time frame to account for the dip-peak effect, which Roger described as "to be expected from the sampling procedure used and (...) not related to "birthday stress' factors". ${ }^{23}$

6. Analyses should not only use pure registry data, but attempts should also be made to include individual patient data that would help to assess the effect of psychosocial factors. In a review, Skala and Freeland ${ }^{30}$ called for prospective study designs in future research.

7. Results should not be communicated by $p$ values, as these confound the size of the effect with its precision, but by using effect estimates with corresponding confidence intervals (CIs). Statistical testing becomes particularly useless in very large samples where nearly all statistical tests used would achieve statistical significance, irrespective of the subject matter relevance of the effect.

8. As most studies tested holiday effects in several subgroups it is necessary to take multiple testing into account.

9. Taking previous findings into account, the analysis of sociodemographic characteristics such as marital status, age, sex, religious affiliation are important to consider as they might affect hastening/postponement effects.

We tried to take these aspects into account which is described in more detail in the methods section.

\section{METHODS}

The data were obtained from the microdata set of official statistics provided for scientific use by the "Research Data Centres (RDC) of the Federal Statistical Office". ${ }^{31}$ The anonymised data set included all deaths registered in Germany from 1995 to 2009, that is 3257520 individual cancer deaths in total. For each cancer death, information such as cause of death encoded by the
International Classification of Diseases (ICD), place of birth, sex, date of birth and death was available. The cause of death is defined as the underlying disease that began a causal chain leading to death. We used the ICD-10 to decipher disease entities occurring after 1997 and the ICD-9 for earlier cases. Individuals born on 29 February were excluded from the analysis. In the case of Christmas and Easter (Christian holidays) we excluded all decedents with non-Christian (eg, Islamic, Jewish) religious affiliation (2.3\% of the total sample). The research proposal was approved by the data providing Federal Statistical Office. As we used exclusively register data, no written consent, approval of an ethics committee or Institutional Review Board was required. Anonymity was ensured by the Research Data Centres of the Federal Statistical Office.

Data access and analysis was undertaken via 'remote execution' whereby the user compiles an evaluation programme by using dummy files, which is transmitted to the RDC. The programme itself is subsequently executed by the RDC and the results are sent back to the user.

As biographical events we examined birthday, Christmas and Easter by comparing deaths over a total period of 2 weeks with the event of interest at the mid point. Following previous studies, the event itself marked the last day of the first week ${ }^{21}: 25$ December ( 7 January in the case of Christian-Orthodox affiliation) was the last day of the preChristmas period, 26 December the first day of the following week (week before=six preceding days+event; week after=seven following days). Easter Sunday (Orthodox Easter in the case of Christian-Orthodox affiliation) was assumed to be the last day of the preEaster period. Additionally, a total period of 4 weeks ( 2 weeks before and after the event) was examined separately as a sensitivity analysis.

Malignancy was classified by sorting, separately for men and women, the 10 most common tumour entities by their 5 -year survival rate. ${ }^{32} 33$ The three most aggressive entities were considered high, the next four were classed as medium and the three remaining were classified as low malignant. Less common forms were summarised as 'unknown malignancy' (table 1).

Concerning religion, we differentiated between believers (affiliation to a Christian confession) and atheists (no affiliation to a Christian confession), and unknown affiliation. To observe geographical effects, Germany's federal states were sorted into groups along a NorthSouth and a West-East axis (table 2), as there are socioeconomic differences between these regions.

\section{The problem of age group and birthday}

Based on the argument of Roger, ${ }^{23}$ we raised the threshold of age groups by 15 days when analysing the event of birthday. Using this approach the limit of an age group was not the actual birthday, but the day 15 days after the birthday (limit lies beyond the maximum observation time of 14 days around an event). Thus, the boundary 
Table 1 Malignancy ordered by 5-year survival rate with related cancer entities and ICD for men and women ${ }^{32} 33$

\begin{tabular}{|c|c|c|c|c|c|c|}
\hline \multirow[b]{2}{*}{ Malignancy } & \multicolumn{3}{|l|}{ Men } & \multicolumn{3}{|l|}{ Women } \\
\hline & Entity of tumour & ICD-9 & ICD-10 & Entity of tumour & ICD-9 & ICD-10 \\
\hline \multirow[t]{3}{*}{1} & Melanoma & 172 & $\mathrm{C} 43$ & Melanoma & 172 & $\mathrm{C} 43$ \\
\hline & Prostate & 185 & C61 & Breast & 174 & $\mathrm{C} 40$ \\
\hline & Bladder & 188 & C67, D09.0, D41.4 & Corpus uteri & $182 / 179$ & C54/C55 \\
\hline \multirow[t]{4}{*}{2} & Non-Hodgkin lymphoma & $200 / 202$ & C82-85 & Cervix uteri & 180 & C53 \\
\hline & Oral cavity and pharynx & $140-149$ & $\mathrm{C} 00-\mathrm{C} 14$ & Bladder & 188 & C67, D09.0, D41.4 \\
\hline & Kidney & 189 & C64 & Colon and rectum & $153 / 154$ & $\mathrm{C} 18-\mathrm{C} 21$ \\
\hline & Colon and rectum & $153 / 154$ & $\mathrm{C} 18-\mathrm{C} 21$ & Ovary and adnexa & 183 & C56 \\
\hline \multirow[t]{3}{*}{3} & Stomach & 151 & C16 & Stomach & 151 & C16 \\
\hline & Lung and bronchus & 162 & C33-C34 & Lung and bronchus & 162 & C33-C34 \\
\hline & Pancreas & 157 & $\mathrm{C} 25$ & Pancreas & 157 & $\mathrm{C} 25$ \\
\hline
\end{tabular}

that excludes cases of younger age remains outside the observed time frame.

\section{Trend correction}

As figure 1 illustrates, there is an underlying trend for death numbers within 1 year, showing a minimum in the summer and increasing deaths as winter approaches. We de-trended our data by fitting a sinus function and performed all analyses on the adjusted data. Details are given in the online supplementary appendix.

\section{Statistical analysis}

We computed relative risks (RRs) with the corresponding CIs corrected for multiple testing, the number needed to observe (NNO), and the relative number of postponed deaths per 1000 cases. For all these effect measures, deaths after the event were regarded as the outcome of interest. The following example illustrates the parameters and their interpretation: considering 100 cases, under the null hypothesis of no effect of an event we would expect 50

\begin{tabular}{|c|c|}
\hline Region & Federal state \\
\hline \multicolumn{2}{|c|}{ North-South } \\
\hline North & $\begin{array}{l}\text { Schleswig-Holstein, Lower Saxony, } \\
\text { Mecklenburg, Hamburg and Bremen }\end{array}$ \\
\hline Middle & $\begin{array}{l}\text { Brandenburg, Saxony, Saxony-Anhalt, } \\
\text { Thuringia, Hesse, Rhineland-Palatinate, } \\
\text { North Rhine-Westphalia, Saarland and } \\
\text { Berlin }\end{array}$ \\
\hline $\begin{array}{l}\text { South } \\
\text { West-East }\end{array}$ & Bavaria and Baden-Wuerttemberg \\
\hline West & $\begin{array}{l}\text { Schleswig-Holstein, Lower Saxony, Hesse, } \\
\text { Rhineland-Palatinate, North } \\
\text { Rhine-Westphalia, Saarland, Bavaria, } \\
\text { Baden-Wuerttemberg, Hamburg and } \\
\text { Bremen }\end{array}$ \\
\hline East & $\begin{array}{l}\text { Brandenburg, Saxony, Saxony-Anhalt, } \\
\text { Thuringia, Berlin and Mecklenburg }\end{array}$ \\
\hline
\end{tabular}

deaths before and 50 after the event. If one death is moved to the period after the event, the number changes to 49 cases in the first period and 51 in the second, which is equivalent to one postponed death. In order to find one further deferred death one needs to observe 100 cases again, which is represented by a NNO of 100 . The postponed death increases the proportion of a death after the event by a factor of 1.02 (RR) in comparison to the sample without postponement. That is, RRs larger than one and positive NNO and number of postponed deaths depict postponements of death until after an event.

In order to test for differences between death numbers before and after an event, an exact binomial test (twotailed) with the null hypothesis of $\mathrm{p}=0.5^{21}$ was performed. The limit of significance was assumed as $\alpha=0.05$. To adjust for multiple testing, a Bonferroni-corrected $\alpha$ of 0.05 / $(3 \times 29)=0.000574$ was finally considered. An interaction test was performed to examine homogeneity between subgroups. Figure 2 illustrates the day-by-day pattern of all cancer deaths taken into account.

In terms of statistical power, with an exemplary number of 120000 cases in the window of 2 weeks, we could detect an absolute drop or peak of $1 \%$ in the observed predeviation/postproportion with a probability of $99.9 \%$.

All statistical analysis and data management was performed using SAS, V.9.2 (SAS Inc, Cary, North Carolina, USA).

\section{RESULTS}

\section{Birthdays}

When all cases were taken into account, the observed RR was almost one (figure 3). As the day-by-day pattern (figure 2) revealed, only a little peak of deaths at birthdays itself, but not around this occasion could be seen. In the subgroups by age, adapted for the effect described by Roger (see the online supplementary appendix for results with 'Roger effect'), almost no relevant death pattern was observed, which is also true for various other subgroups. The strong effect in the youngest age group was not significant due to low case numbers. A different association between grades 


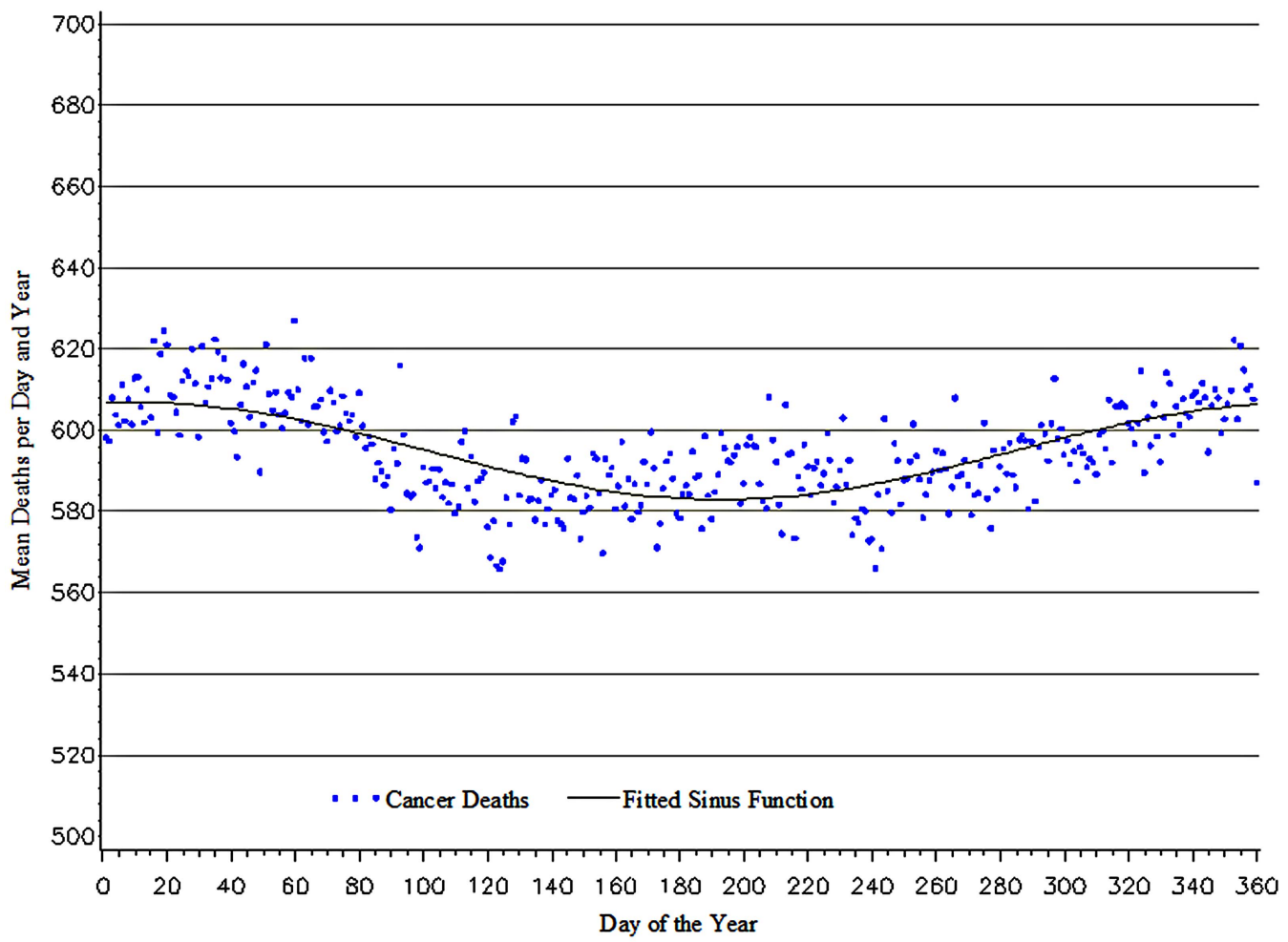

Figure 1 Total cancer deaths per day of year. Average deaths per day. A sinus curve (considering the repetitive character of a year) was fitted to the time series.

of malignancy or regions could not be deduced from our data. Thus we could neither attribute a hastening nor a postponement of death around birthdays. Furthermore, there were no convincing intrasubgroup differences.

\section{Christmas}

For Christmas, a convincing shift of deaths to the earlier week was found for the complete sample (figure 4). The $\mathrm{RR}$ to die in the second week rather than the first was only 0.987 (CI 0.978 to 0.997 ). In total, there were 804 persons who experienced an earlier death than would be expected. This finding is underpinned by the day-by-day pattern in figure 2 showing increased deaths 1 week before Christmas. Deaths within the weeks before and after Christmas are distributed rather evenly, especially without a peak at New Year. Both women and men were more likely to die in the week before Christmas, by an RR of 0.984 (CI 0.970 to 0.998 ) in women and 0.990 (CI 0.976 to 1.003 ) in men. The similarity in effect sizes between sexes is reflected by a non-significant interaction ( $\mathrm{p}=0.332$ ) indicating comparable hastening effects in men and women. Estimates of RRs were fairly similar between age subgroups ranging between 0.981 and 0.984 . In the age group of 40-45 years, a remarkably low RR of 0.939 (CI 0.859 to 1.019 ) was estimated leading to an NNO of only 33 , which was however not significant.

Again there were no relevant differences between grades of malignancy. In the different categories of family status, we found a statistically convincing effect only in the subgroup of married individuals. In atheists and religious people the number of deaths in the preperiod exceeded the number in the following week, which was significant in the subgroup of believers due to a larger case number. Considering regions we calculated only moderate estimates which appeared to be homogenous within subgroups.

\section{Easter}

The results within the subgroups taken into account were only weak and appeared to undulate around the null effect value (figure 5). Small deviations from this value are most likely due to random variations as there were no convincing estimates when corresponding CIs are taken into account.

\section{Sensitivity analysis}

Analysing the results for a total time window of 4 weeks, 2 weeks before and after the specific event, no meaningful deviances from the previous findings were found. In some instances, results were statistically significant as case numbers nearly doubled, however, estimates remained almost unchanged (see also supplementary figures A1-A3 in the online supplementary appendix). For the Christmas effect, estimates were in general smaller in the 4-week analysis.

\section{DISCUSSION}

Summarising our results we found more deaths in the week before Christmas across several subgroups, while 


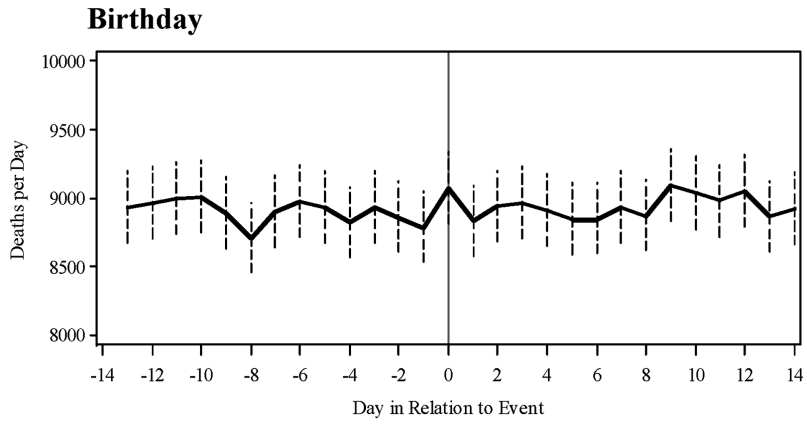

Christmas

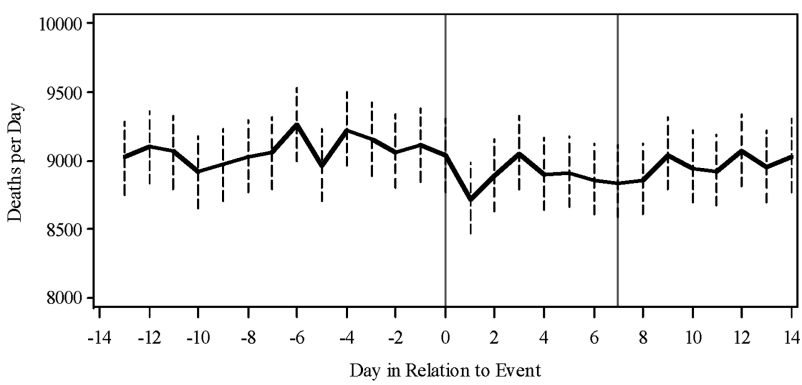

Easter

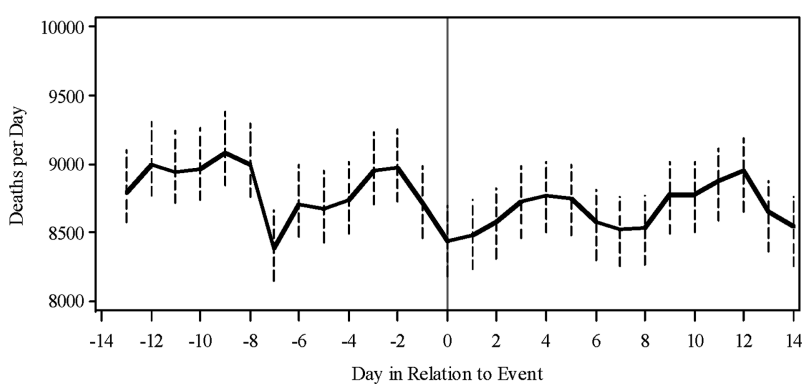

Figure 2 Day by day pattern of all cancer deaths around birthdays, Christmas, and Easter. The vertical (grey) line marks the event of interest (day=0). The second grey line $($ day $=7)$ of the graph depicting the pattern of Christmas marks New Year. Black dashed lines indicate $95 \% \mathrm{Cl}$ (obtained from Poisson distributions using the SAS procedure of PROC GENMOD). Death numbers were corrected for seasonality.

there was little evidence of hastening or postponement of death around Easter or birthdays.

\section{Birthday}

In line with our findings previous studies ${ }^{20} 21$ were not able to unveil any remarkable mortality patterns. However, considering age effects Young and Hade ${ }^{21}$ only distinguished between people older and younger than 70 and did not control for the bias effect described by Roger. ${ }^{23}$ We did not find any difference between men and women in their ability to postpone death, as proposed by Phillips et al. ${ }^{16}$ However, in contrast to our study, these authors referred to a wider time frame of a whole year. The null effect found in the subgroup of family status is in contrast to previous findings, which found a postponement in people who have never married. ${ }^{19}$ Grigsby ${ }^{34}$ found, by comparing the mortality of the birth month to other months, that non-married people have a "larger month effect than does the married group". Considering malignancy we found no relevant effects such as stronger effects in deaths from less malignant tumours.

\section{Christmas}

Our study indicated a predominance of deaths in the prior period (statistically significant in women, married individuals, believers, cases from the western regions and the complete sample); therefore the prospect of Christmas seemed to reduce the chance to survive this date.

When we compare our finding of a hastening of death with other studies, the contrast with the results of Shimizu and Pelham ${ }^{14}$ might be explained by short-term peaks at Christmas due to deaths from cardiac causes. ${ }^{25}{ }^{27}$ Young and Hade $^{21}$ did not unveil any significant death pattern, which is possibly due to examining only a low number of cases.

Coming back to the mechanisms presented in the discussion, we found evidence of negative influences such as increased distress to be present before Christmas surpassing possible positive aspects of this holiday, which might in turn advance tumour progressive effects of the HPA $^{2} 7$ or growth factors. ${ }^{8}$ Nevertheless, we cannot attribute a certain cause (immunological, social) underlying these changes. Hillard $e t a l^{55}$ revealed that there was no data based increase in acute psychological disorders on and before Christmas, which weakens a psychological explanation. However, there are tendencies for a depressed mental status during the Christmas period, mainly due to concerns such as loneliness and absence of family, ${ }^{36}$ which support our findings and lead to a possible interaction of social support and distress.

As we focused on the specific collective of patients with cancer other mechanisms such as particularities in social relations or deprivation, ${ }^{37}$ and pathological affections of the body, for example, chronic inflammation is associated with a depressed mood, ${ }^{38}$ might be in action. The importance of social relations can be concluded from the fact that people living alone perceive the absence of relatives as a disadvantage and rely more on the continuous presence of professional health workers. ${ }^{39}$ The interruption of these relations prior to Christmas might contribute to distress in patients with cancer before Christmas. ${ }^{39}$ An increased sensibility ${ }^{40}$ while expecting Christmas combined with a depressed mood in the face of death might be an additional factor contributing to this phenomenon. Surprisingly, singles did not show a hastening of death as it was the case for the majority of subgroups, which was similarly found by Byers et al. ${ }^{19}$ For singles, Christmas might be a time to develop and renew social relations weakening a relative social isolation, ${ }^{42}$ giving pleasure ${ }^{43}$ and possibly culminating in a relief of cancer-related distress.

Apart from the mentioned, it is plausible that the intensity of treatment is reduced before Christmas. In addition to potential staff shortages, it is possible that patients may wish to receive attenuated treatment. 


\begin{tabular}{|c|c|c|c|c|c|c|c|c|c|}
\hline Groups & Subgroups & Before Event & Rel. Risk [CI] & $\begin{array}{l}\text { Cases } \\
\text { before }\end{array}$ & after & $\begin{array}{l}\text { Postp. deaths } \\
\text { absol. } 1 / 1000\end{array}$ & NNO & $\begin{array}{l}p \text {-Value } \\
\text { Binomial }\end{array}$ & $\begin{array}{l}\text { p-Value } \\
\text { Interac. }\end{array}$ \\
\hline All & All & $|+|$ & $0.999[0.989,1.009]$ & 62372 & 62275 & $\begin{array}{ll}-48.5 & -0.4 \\
\end{array}$ & -2570 & 0.786 & \\
\hline \multirow[t]{2}{*}{ Gender } & Women & $F+1$ & $0.999 \quad[0.985,1.013]$ & 29710 & 29651 & \begin{tabular}{ll|}
-29.5 & -0.5 \\
\end{tabular} & -2012 & 0.812 & \multirow[t]{2}{*}{0.946} \\
\hline & Men & $F+1$ & $0.999 \quad[0.986,1.013]$ & 32663 & 32623 & $-20 \quad-0.3$ & -3264 & 0.879 & \\
\hline \multirow[t]{10}{*}{ Age } & $>80 \mathrm{yr}$ & $1+-1$ & $0.996[0.977,1.015]$ & 16769 & 16638 & -65.5 & -510 & 0.477 & \multirow[t]{10}{*}{0.087} \\
\hline & $75-80 \mathrm{yr}$ & $\mapsto$ & $0.998[0.973,1.023]$ & 9583 & 9547 & $\begin{array}{ll}-18 & -0.9 \\
\end{array}$ & -1063 & 0.800 & \\
\hline & $70-75 \mathrm{yr}$ & $\mapsto-1$ & $0.996[0.971,1.021]$ & 9687 & 9616 & $\begin{array}{ll}-35.5 & -1.8 \\
\end{array}$ & -544 & 0.614 & \\
\hline & $65-70 \mathrm{yr}$ & $\mapsto \div$ & $0.987 \quad[0.961,1.013]$ & 8736 & 8515 & $\begin{array}{ll}-110.5 & -6.4 \\
\end{array}$ & -156 & 0.094 & \\
\hline & $60-65 \mathrm{yr}$ & $\longmapsto$ & $0.997 \quad[0.967,1.027]$ & 6545 & 6509 & $-18 \quad-1.4$ & -725 & 0.759 & \\
\hline & $55-60 \mathrm{yr}$ & $\vdash \cdot-1$ & $1.009 \quad[0.973,1.045]$ & 4565 & 4647 & \begin{tabular}{ll|}
41 & 4.5 \\
\end{tabular} & 225 & 0.399 & \\
\hline & $50-55 \mathrm{yr}$ & $\longmapsto 1 \cdot-\mid$ & $1.014 \quad[0.968,1.060]$ & 2795 & 2876 & 40.5 & 140 & 0.288 & \\
\hline & $45-50 \mathrm{yr}$ & 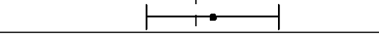 & $1.015[0.957,1.073]$ & 1755 & 1809 & $27 \quad 7.6$ & 132 & 0.375 & \\
\hline & $40-45 \mathrm{yr}$ & $\frac{1}{1} \cdot$ & $1.027[0.947,1.106]$ & 930 & 981 & 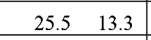 & 75 & 0.253 & \\
\hline & $<40 \mathrm{yr}$ & $\mathrm{H}$ & $1.059 \quad[0.984,1.133]$ & 1009 & 1135 & $\begin{array}{ll}63 & 29.4 \\
\end{array}$ & 34 & 0.007 & \\
\hline \multirow[t]{4}{*}{ Malignancy } & High & $1 \cdot \because$ & $0.992 \quad[0.975,1.010]$ & 18779 & 18499 & $-140-3.8$ & -266 & 0.148 & \multirow[t]{4}{*}{0.194} \\
\hline & Medium & $\mapsto-1$ & $1.001 \quad[0.980,1.022]$ & 13633 & 13653 & $\begin{array}{|ll|}10 & 0.4 \\
\end{array}$ & 2729 & 0.908 & \\
\hline & Low & ⺊. & $0.995[0.971,1.018]$ & 10869 & 10752 & $\begin{array}{ll}-58.5 & -2.7 \\
\end{array}$ & -370 & 0.430 & \\
\hline & Not def. & $1+-1$ & $1.007 \quad[0.990,1.025]$ & 19091 & 19371 & $140 \quad 3.6$ & 275 & 0.155 & \\
\hline \multirow[t]{4}{*}{ Family stat. } & Divorced & $\longmapsto \cdot 1$ & $0.989[0.953,1.025]$ & 4679 & 4575 & $\begin{array}{ll}-52 & -5.6\end{array}$ & -178 & 0.284 & \multirow[t]{4}{*}{0.003} \\
\hline & Widowed & $1 \cdot 4$ & $0.991[0.973,1.009]$ & 19027 & 18683 & $\begin{array}{ll}-172 & -4.6 \\
\end{array}$ & -219 & 0.077 & \\
\hline & Married & $\mathrm{FeH}$ & $1.001[0.987,1.014]$ & 34094 & 34139 & $22.5 \quad 0.3$ & 3033 & 0.866 & \\
\hline & Single & $\Perp$ & $1.032[0.997,1.068]$ & 4555 & 4858 & $\begin{array}{ll}151.5 & 16.1 \\
\end{array}$ & 62 & 0.002 & \\
\hline \multirow[t]{3}{*}{ Religion } & Atheists & $\mapsto-1$ & $0.999 \quad[0.978,1.021]$ & 12792 & 12779 & $\begin{array}{ll}-6.5 & -0.3 \\
\end{array}$ & -3934 & 0.940 & \multirow[t]{3}{*}{0.576} \\
\hline & Believers & $\mathrm{H}$ & $1.000[0.989,1.011]$ & 47954 & 47931 & $\begin{array}{ll}-11.5 & -0.1 \\
\end{array}$ & -8338 & 0.943 & \\
\hline & Unknown & $\longmapsto$ & $0.981[0.920,1.042]$ & 1626 & 1565 & $-30.5 \quad-9.6$ & -105 & 0.288 & \\
\hline \multirow[t]{3}{*}{ Region: N-S } & North & $1 \div 4$ & $0.994 \quad[0.974,1.013]$ & 16043 & 15836 & \begin{tabular}{ll|}
-103.5 & -3.2 \\
\end{tabular} & -308 & 0.249 & \multirow[t]{3}{*}{0.447} \\
\hline & Central & $1 \cdot-1$ & $1.000 \quad[0.987,1.013]$ & 34583 & 34607 & $12 \quad 0.2$ & 5766 & 0.930 & \\
\hline & South & $\mapsto-1$ & $1.004 \quad[0.981,1.026]$ & 11745 & 11833 & $\begin{array}{ll}44 & 1.9\end{array}$ & 536 & 0.571 & \\
\hline \multirow[t]{2}{*}{ Region: W-E } & East & 1.4 & $0.991 \quad[0.970,1.012]$ & 13336 & 13098 & $\begin{array}{ll}-119 & -4.5 \\
\end{array}$ & -222 & 0.145 & \multirow[t]{2}{*}{0.132} \\
\hline & West & $1-1$. & $1.001[0.990,1.012]$ & 49036 & 49177 & 70.5 & 1393 & 0.655 & \\
\hline
\end{tabular}

Figure 3 Deaths from cancer during one week before and after birthday in Germany from 1995-2009 with related parameters. Abbreviations: Cl: Confidence interval; NNO: Number needed to observe; Rel. Risk.: Relative risk to die in the week after Christmas, Reg. N-S: Regions along North-South axis, Reg. W-E: Regions along West-East axis. p-value Binomial: Obtained from an exact binomial test with a null hypothesis proportion of $p=0.5$ of all deaths to occur in each week out of the total time window of two weeks. $p$-value Interaction: $p$-value for test of interaction.

A decrease in survival rates in hospitals on Christmas and weekends has been reported $^{44}$; however, these related to acute diseases. It might be possible that fewer (elective) operations are performed between Christmas and New Year, and thus we would observe a decreased mortality associated with surgery. Nevertheless, elective operations are rarely performed on patients in an advanced cancer stage. Furthermore, deaths due to accidents during operations would not be attributed to cancer by the RDC.

In terms of the time window of 4 weeks, effect estimates were weaker indicating the short-term effect of the hastening, which is also supported by the day-by-day pattern (figure 2) with a maximum 6 days before Christmas. As the number of deaths peaks several days before Christmas when considerable staff shortages are not to be expected the distress hypothesis seems indeed to be more plausible, while the key role of the HPA was emphasised by previous studies. ${ }^{27}$ In consequence, the process of growing distress might start even earlier and just cumulate few days before Christmas.

Coming to the behavioural component it might be possible that nutrition and physical activity of patients with cancer worsens before Christmas; however, data supporting this statement are not sufficiently available. It was reported that Christmas is a difficult time for obese to stick to a certain diet regime ${ }^{45}$ and that artificial and palliative nutrition procedures may be adapted for patients' needs around Christmas. ${ }^{46} 47$ Thus, a looser nutrition concept might worsen survival leading to more deaths before Christmas; however, the evidence is weak. Similarly, physical activity might decrease before Christmas; but the seasonal effect of winter time is difficult to distinguish from an actual 'Christmas effect'.

A postponement of death (reduction of distress) was not observed. Indeed, taking the study by Kornblith et $a l^{11}$ into account (social support affecting peoples' emotional state needs to be very high to reduce distress) the small effect sizes in our study make it difficult to observe a distress reduction (which might only be achieved for a minority) over all observed cancer deaths.

In terms of religiosity, similar hastening effects in religious people and atheists might reflect a similarly attributed meaning to Christmas and a change from a primarily religious feast to a secular holiday in Germany. In our sample there were no considerable regional effect differences indicating the low influence of local factors such as socioeconomic and demographic characteristics. 


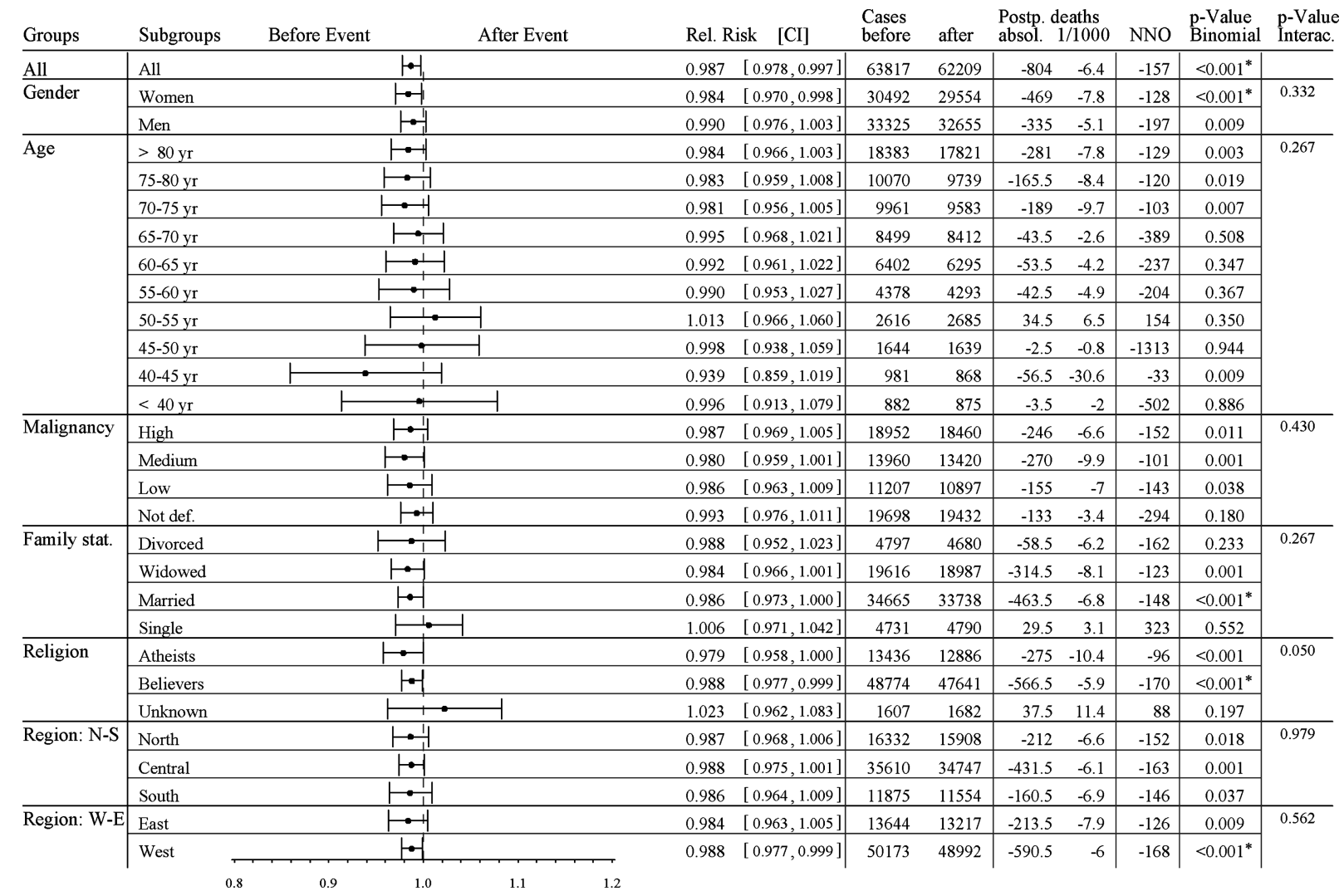

Figure 4 Deaths from cancer during one week before and after Christmas in Germany from 1995-2009 with related parameters. Abbreviations: Cl: Confidence interval; NNO: Number needed to observe; Rel. Risk.: Relative risk to die in the week after Christmas, Reg. N-S: Regions along North-South axis, Reg. W-E: Regions along West-East axis. p-value Binomial: Obtained from an exact binomial test with a null hypothesis proportion of $p=0.5$ of all deaths to occur in each week out of the total time window of two weeks. p-value Interaction: $p$-value for test of interaction.

\section{Easter}

In the case of Easter again all effects of this occasion are likely to be caused by random fluctuation. Previous studies $^{27} 28$ could also not find any relevant mortality pattern and our results also failed to reveal consistent effects. The weak effects observed for Easter might be mainly due to lower importance of this holiday compared with Christmas in Germany.

\section{Limitations and future research}

Considering the mentioned limitations of previous studies we integrated almost all points in our study design, but certainly failed to conduct a prospective study (point 6). In a review of previous retrospective studies Skala and Freedland ${ }^{30}$ could not find any evidence for any postponement of death. To overcome this problem, a prospective study was proposed providing deeper insights into the physiological mechanisms underlying the psychological affection of death. As we used retrospective data, we failed to take individual data such as the will to live, clinical setting, mental condition and the treatment received by the decedent into account. A prospective examination could reveal stronger postponement effects, but would also lead to a dramatic reduction in the number of cases. Furthermore, ethical aspects have to be considered and there is certain risk of only few patients consenting to such a study while facing death, thus potentially limiting representability. However, in our study we have identified subgroups and events for which people tend to hasten or postpone their death, which could serve as a starting point for future research.

Other biographical events apart from those we investigated are probably more important to people, and might reveal stronger indications for a postponement of death. A grandchild's birth or a child's school enrolment could induce a massive will to live. However, as these events are not generally known, it is hardly possible to consider them.

Finally, it is known that only less than $50 \%^{48} 49$ of the causes registered on the death certificate show the actual cause. To avoid such inaccuracies, the certificate would need to be re-evaluated individually by autopsy, which is hardly feasible. It will be the challenge of future research to solve these difficulties. However, in our case, inaccuracies would only cause bias if errors in death certificates would be systematically different before and after the respective biographical event which seems not very realistic.

Restrictions due to data privacy regulations of the RDCs are a further limitation of our study. Because of the possibility of de-anonymising single cases, data are 


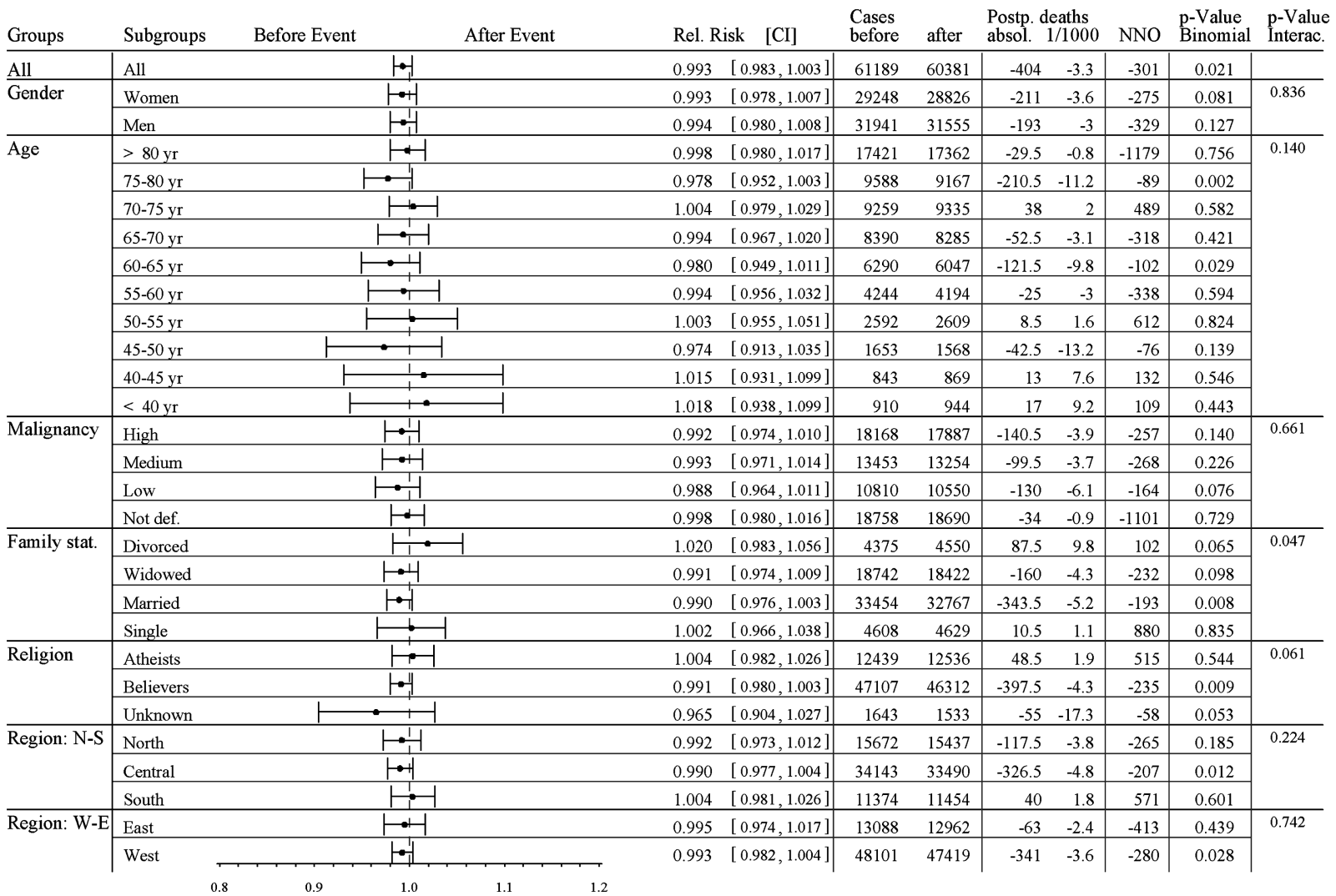

Figure 5 Deaths from cancer during one week before and after Easter in Germany from 1995-2009 with related parameters. Abbreviations: Cl: Confidence interval; NNO: Number needed to observe; Rel. Risk.: Relative risk to die in the week after Christmas, Reg. N-S: Regions along North-South axis, Reg. W-E: Regions along West-East axis. p-value Binomial: Obtained from an exact binomial test with a null hypothesis proportion of $p=0.5$ of all deaths to occur in each week out of the total time window of two weeks. $p$-value Interaction: $p$-value for test of interaction.

only accessible in not-too-sparse strata, obviating all analyses that use individual case data, for example, regression analyses with simultaneous adjustments for more than one confounder, or even interactions between confounders.

In spite of these limitations, our data revealed a remarkable hastening of cancer deaths in the period before Christmas. In contrast, there is no persuasive evidence of a postponement until after any event, which underlines that people cannot prolong life on a relevant scale. Practically, this finding implies that the advent season is a vulnerable time for a dying person, who therefore requires especially focused care at that time. Moreover, the hastening of death identified requires further scientific investigation as a wide range of people are adversely affected.

Contributors DM organised data access and communication with the "Research Data Centres", performed the statistical analysis, and drafted the manuscript. He is the guarantor. OK had the initial study idea, assisted with planning of the study, data analysis and data interpretation and revised the manuscript critically for important intellectual content.

Funding This research received no specific grant from any funding agency in the public, commercial or not-for-profit sectors.

Competing interests None.

Ethics approval As we used mere register data, an approval from an Ethics Committee/Institutional Review Board approval was not required.
Provenance and peer review Not commissioned; externally peer reviewed.

Data sharing statement No additional data are available.

Open Access This is an Open Access article distributed in accordance with the Creative Commons Attribution Non Commercial (CC BY-NC 3.0) license, which permits others to distribute, remix, adapt, build upon this work noncommercially, and license their derivative works on different terms, provided the original work is properly cited and the use is non-commercial. See: http:// creativecommons.org/licenses/by-nc/3.0/

\section{REFERENCES}

1. Butler LD, Koopman C, Cordova MJ, et al. Psychological distress and pain significantly increase before death in metastatic breast cancer patients. Psychosom Med 2003;65:416-26.

2. Peters EMJ. Psychological support of skin cancer patients. $\mathrm{Br} \mathrm{J}$ Dermatol 2012;167(Suppl 2):105-10.

3. Allen-Mersh T, Earlam S, Fordy C, et al. Quality of life and survival with continuous hepatic-artery floxuridine infusion for colorectal liver metastases. Lancet 1994;344:1255-60.

4. Wium-Andersen MK. Elevated C-reactive protein levels, psychological distress, and depression in 73131 individuals elevated CRP levels and psychiatric illness. JAMA Psychiatry 2013;70:176.

5. Nozawa K, Shimizu C, Kakimoto M, et al. Quantitative assessment of appearance changes and related distress in cancer patients. Psychooncology 2013;22:2140-7.

6. Admiraal JM, Reyners AKL, Hoekstra-Weebers JEHM. Do cancer and treatment type affect distress? Psychooncology 2013;22:1766-73.

7. Spiegel D, Sephton SE, Terr AI, et al. Effects of psychosocial treatment in prolonging cancer survival may be mediated by neuroimmune pathways. Ann N Y Acad Sci 1998;840:674-83. 
8. Fang $\mathrm{CY}$, Egleston $\mathrm{BL}$, Ridge JA, et al. Psychosocial functioning and vascular endothelial growth factor in patients with head and neck cancer. Head Neck 26 Jun 2013. Epub ahead of print.

9. Bellardita L, Rancati T, Alvisi MF, et al. Predictors of health-related quality of life and adjustment to prostate cancer during active surveillance. Eur Urol 2013;64:30-6.

10. Kroenke $\mathrm{CH}$, Michael $\mathrm{Y}$, Tindle $\mathrm{H}$, et al. Social networks, social support and burden in relationships, and mortality after breast cancer diagnosis. Breast Cancer Res Treat 2012;133:375-85.

11. Kornblith AB, Herndon JE, Zuckerman E, et al. Social support as a buffer to the psychological impact of stressful life events in women with breast cancer. Cancer 2001;91:443-54.

12. de Boer MF, Ryckman RM, Pruyn JF, et al. Psychosocial correlates of cancer relapse and survival: a literature review. Patient Educ Couns 1999;37:215-30.

13. Aizer AA, Chen M, McCarthy EP, et al. Marital status and survival in patients with cancer. J Clin Oncol 2013;31:3869-76.

14. Shimizu M, Pelham BW. Postponing a date with the grim reaper: ceremonial events and mortality. Basic Appl Soc Psych 2008;30:36-45.

15. Baumann FT, Bloch W, Weissen A, et al. Physical activity in breast cancer patients during medical treatment and in the aftercare-a review. Breast Care (Basel) 2013;8:330-4.

16. Phillips DP, van Voorhees CA, Todd RE. The birthday: lifeline or deadline? Psychosom Med 1992;54:532-42.

17. Davies NJ, Batehup L, Thomas R. The role of diet and physical activity in breast, colorectal, and prostate cancer survivorship: a review of the literature. Br J Cancer 2011;105(Suppl 1):S52-73.

18. Seretakis $\mathrm{D}$, Lagiou $\mathrm{P}$, Lipworth $\mathrm{L}$, et al. Changing seasonality of mortality from coronary heart disease. JAMA 1997;278:1012-14.

19. Byers B, Zeller RA, Byers PY. Birthdate and mortality: an evaluation of the death-dip/death-rise. Sociol Focus 1991;24:13-28.

20. Brown JK, Knapp TR. Do people with cancer postpone death to celebrate special occasions? Cancer Pract 1995;3:351-5.

21. Young DC, Hade E. Holidays, birthdays, and postponement of cancer death. JAMA 2004;292:3012-16.

22. Alderson M. Relationship between month of birth and month of death in the elderly. Br J Prev Soc Med 1975;29:151-6.

23. Roger JH. An explanation for the observed increase in mortality after a birthday in people over 75 years old. Br J Prev Soc Med 1977;31:62-4

24. Phillips D, Barker GE, Brewer KM. Christmas and New Year as risk factors for death. Soc Sci Med 2010;71:1463-71.

25. Phillips DP, Jarvinen JR, Abramson IS, et al. Cardiac mortality is higher around Christmas and New Year's than at any other time: the holidays as a risk factor for death. Circulation 2004:110:3781-8.

26. Kloner RA. The "Merry Christmas Coronary" and "Happy New Year Heart Attack" phenomenon. Circulation 2004;110:3744-5.

27. Milne EMG. Mortality spike at New Year but not Christmas in North East England. Eur J Epidemiol 2005;20:849-54.

28. Walker L, Walker LD. Anniversary reaction: important events and timing of death in a group of Roman Catholic priests. OMEGA 1990;21:69-74.

29. Healy JD. Excess winter mortality in Europe: a cross country analysis identifying key risk factors. $J$ Epidemiol Community Health 2003;57:784-9.
30. Skala JA, Freedland KE. Death takes a raincheck. Psychosom Med 2004;66:382-6.

31. A standard for the release of microdata. Wiesbaden: Statistische Ämter des Bundes und der Länder. ("Research Data Centres of the Federal Statistical Office and the statistical offices of the Länder"), ed. 2006.

32. Coleman MP, Rachet B, Woods LM, et al. Trends and socioeconomic inequalities in cancer survival in England and Wales up to 2001. Br J Cancer 2004:90:1367-73.

33. Brenner $\mathrm{H}$. Long-term survival rates of cancer patients achieved by the end of the 20th century: a period analysis. Lancet 2002;360:1131-5.

34. Grigsby JS. Special occasions, stress, and mortality: do people tend to die during their birth month? Soc Biol 1985;32:102-14.

35. Hillard JR, Holland JM, Ramm D. Christmas and psychopathology. Data from a psychiatric emergency room population. Arch Gen Psychiatry 1981;38:1377-81.

36. Ajdacic-Gross V, Knöpfli D, Landolt K, et al. Death has a preference for birthdays - an analysis of death time series. Ann Epidemiol 2012;22:603-6.

37. Wright $P$, Smith $A$, Booth $L$, et al. Psychosocial difficulties, deprivation and cancer: three questionnaire studies involving 609 cancer patients. Br J Cancer 2005;93:622-6.

38. Wium-Andersen MK, Ørsted DD, Nielsen SF, et al. Elevated C-reactive protein levels, psychological distress, and depression in 73, 131 individuals. JAMA Psychiatry 2013;70:176-84.

39. Hanratty $\mathrm{B}$, Addington-Hall $\mathrm{J}$, Arthur $\mathrm{A}$, et al. What is different about living alone with cancer in older age? A qualitative study of experiences and preferences for care. BMC Fam Pract 2013;14:22.

40. Hillard JR, Buckman J. Christmas depression. JAMA 1982;248:3175-6.

41. Hairon N. How Christmas festivities and pressures can damage health and well-being. Nurs Times 2008;104:33-4.

42. Ward RA. The never-married in later life. J Gerontol 1979;34:861-9.

43. Ballas D, Dorling D. Measuring the impact of major life events upon happiness. Int J Epidemiol 2007;36:1244-52.

44. Keatinge WR, Donaldson GC. Changes in mortalities and hospital admissions associated with holidays and respiratory illness: implications for medical services. J Eval Clin Pract 2005; 11:275-81.

45. Haug MG. Postponement of cancer death and life insurance. JAMA 2005;293:1592; author reply 1592.

46. Greer S, Morris T, Pettingale KW. Psychological response to breast cancer: effect on outcome. Lancet 1979;2:785-7.

47. House JS, Landis KR, Umberson D. Social relationships and health. Science 1988:241:540-5.

48. Nielsen GP, Björnsson J, Jonasson JG. The accuracy of death certificates. Implications for health statistics. Virchows Arch A Pathol Anat Histopathol 1991;419:143-6.

49. Modelmog D, Rahlenbeck S, Trichopoulos D. Accuracy of death certificates: a population-based, complete-coverage, one-year autopsy study in East Germany. Cancer Causes Control 1992;3:541-6. 